\title{
Electrophysiological perspectives on locus coeruleus: Its role in cognitive versus vegetative functions
}

\author{
HANS-RUDOLF OLPE, MARTIN W. STEINMANN, and ROLAND S. G. JONES \\ Ciba-Geigy Ltd., Basel, Switzerland
}

\begin{abstract}
The hypothesis that the locus coeruleus (LC) may be involved in the control of cognitive and/or vegetative processes is reviewed, primarily focusing on electrophysiological experiments. With the impact of this nucleus on target neurons in different brain areas and with the activity pattern of LC neurons in conscious animals, the electrophysiological data are, to a large extent, in keeping with the postulated role of the LC in cognitive processes. A considerable body of evidence from lesion and stimulation experiments points to a possible function of the LC in the control of autonomic processes. In particular, many studies suggest a role in the central control of blood pressure. The electrophysiological data, although not entirely ruling out such a function, are not in keeping with this hypothesis. In conclusion, although there is a case for the LC's having a role both in the cognitive sphere and in the vegetative sphere, the exact role of the LC in both of them remains to be elucidated.
\end{abstract}

The locus coeruleus (LC) is a brain nucleus which persistently attracts numerous scientists to use a variety of methodological approaches and methods to study its functions. Over the past couple of years, these studies have provided a steadily increasing list of postulated roles for the LC. Unfortunately, this list is not only long but also contains numerous inconsistencies. The primary postulated functions of the LC, most of which have been proposed on the basis of behavioral investigations, are summarized in Figure 1. The suggested functions can be divided arbitrarily into those related to the cognitive sphere and those belonging more to the vegetative or emotional sphere. The role of the LC in the control of attention (Pisa \& Fibiger, 1983) and processes related to learning and memory (Hagan, Alpert, Morris, \& Iversen, 1983; Mair \& McEntee, 1983) is still debated. The amine hypothesis of mood control has still not been proven but remains, at the moment, one of the most attractive hypotheses concerning the etiology of depression. Although a considerable body of clinical and animal experimental data speaks in its favor, it may ultimately turn out to be incorrect.

It is not possible to cover in a single article all the postulated functions of the LC. Therefore, we chose to discuss in a synoptic manner only two aspects of the LC(1) the postulated role in cognitive processes, and (2) functions in the vegetative sphere. Both will be discussed primarily from an electrophysiological point of view. The first topic we selected because most electrophysiological data are in keeping with this hypothesis. The second topic was included because, interestingly enough, it strongly challenges the role of the LC in cog-

The authors' mailing address is: Biology Research Laboratories, Pharmaceuticals Division, Ciba-Geigy Ltd., 4002 Basel, Switzerland.

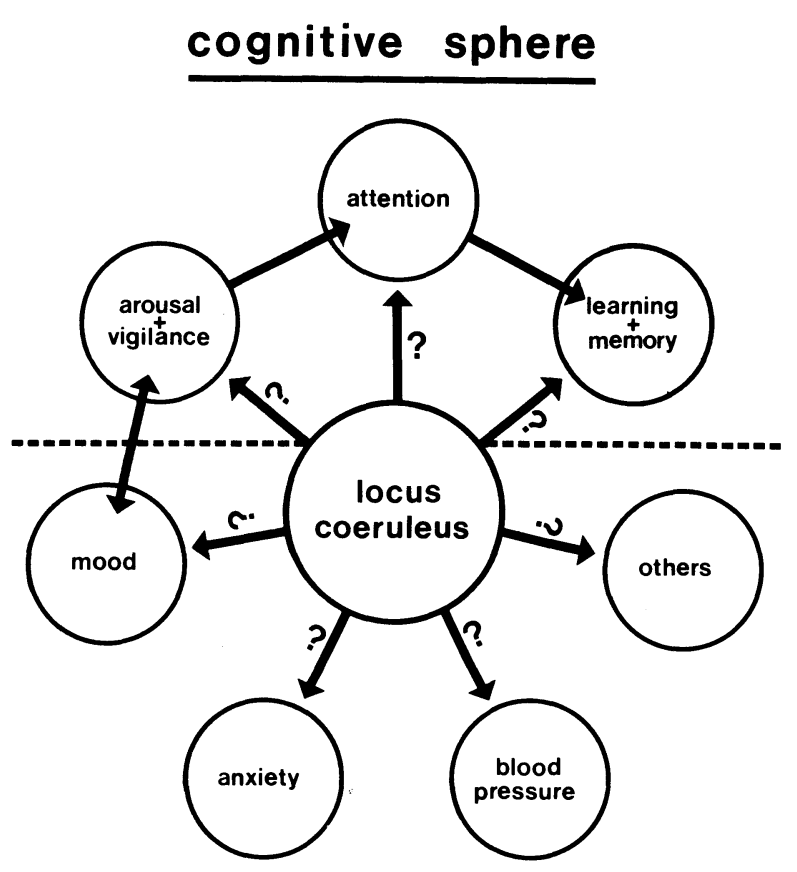

\section{emotional + vegetative sphere}

Figure 1. The main postulated functions of the locus coeruleus are schematically depicted. Several important hypothesized functions are not mentioned. These include brain plasticity, brain metabolism, and brain circulation.

nition. The list of putative functions depicted in Figure 1 is incomplete, and some of those not mentioned will be dealt with in separate papers of this issue. Traditionally, the LC has mostly been considered to be a rather homogeneous, small nucleus composed mainly of 
noradrenergic neurons. The diversity of postulated roles for the LC implies that one has to search for corresponding physiological or anatomical heterogeneity at the level of the nucleus itself.

\section{ELECTROPHYSIOLOGICAL STUDIES SUPPORTING A ROLE IN THE COGNITIVE SPHERE}

\section{The Regulation of LC Neuronal Activity}

The numerous mechanisms that appear to regulate the cellular activity of noradrenergic LC neurons are presented separately. These three influences are those which one might expect to control activity in most neuronal populations, namely (1) intrinsic mechanisms, (2) interneuronal regulatory mechanisms between LC and neurons, and (3) afferent synaptic inputs that activate, suppress, or modulate noradrenergic cell activity. We will not discuss hormonal influences since, apart from the demonstration of the presence of steroid receptors located on LC neurons (Heritage, Grant, \& Stumpf, 1977), there is a paucity of information available on this topic.

Activity of LC neurons in vivo can be arbitrarily divided into two components: tonic and phasic. Tonic activity refers to the fact that the mean spontaneous discharge rate of noradrenergic neurons appears to be quite regular and reflects the behavioral state of the organism (AstonJones \& Bloom, 1981). LC neurons show a low level of regular activity during SWS sleep and an increased level of activity when the animal is awake. During REM sleep, these neurons are practically silent (Aston-Jones \& Bloom, 1981). This tonic discharge pattern is interrupted by phasic bursting activity when the animal is exposed to sensory inputs leading to behavioral arousal. Control of this cellular activity seems likely to depend on a combination of the three processes outlined below.

Intrinsic mechanisms. Neurons of LC discharge action potentials spontaneously in vitro at frequencies of 1 to $5 \mathrm{~Hz}$; similar rates are observed in vivo (Aston-Jones \& Bloom, 1981). LC neurons are spontaneously active in the slice preparation where one might expect extrinsic synaptic influences to be removed. Williams, North, Shefner, Nishi, \& Egan (1984) have shown that there are unlikely to be any ongoing synaptic potentials underlying spontaneous activity, and have suggested that LC neurons have pacemaker-like capabilities. They have proposed a detailed, although speculative, explanation for intrinsic spike production. According to their scheme, spike generation occurs at about $-55 \mathrm{mV}$ when a persistent inward $\mathrm{C}^{2+}$ current exceeds outward (predominantly) $\mathrm{Ca}^{2+}$ activated $\mathrm{K}^{+}$currents. This inward current causes cell depolarization and activation of voltage-dependent $\mathrm{Na}^{+}$ channels. Repolarization involves $\mathrm{K}^{+}$current activation, and the subsequent slow depolarization back to threshold would result from extrusion of $\mathrm{Ca}^{2+}$ that had entered during the action potential. Andrade and Aghajanian (1984) have shown that the postspike afterhyperpolarization seen in $\mathrm{LC}$ neurons is due primarily to a $\mathrm{Ca}^{2+}$-activated $\mathrm{K}^{+}$conductance, and suggested a strong involvement of this current in the control of pacemaker activity in these cells.

Interneuronal regulatory mechanisms of LC. Cedarbaum and Aghajanian (1978) reported that noradrenergic neurons of the rat $\mathrm{LC}$ responded to peripheral nerve stimulation and to noxious stimuli with a burst of spikes, which was followed by a period of firing depression. Antidromic activation of LC neurons was also followed by neuronal depression (Aghajanian, Cedarbaum, \& Wang, 1977). On the basis of anatomical and electrophysiological investigations, it was concluded that these inhibitions were mediated by recurrent LC collaterals (Cedarbaum \& Aghajanian, 1978). The firing depression induced by dorsal bundle, antidromic stimulation was antagonized by the alpha-antagonist piperoxane (Aghajanian et al., 1977), and this agent also blocked the inhibition of LC cells by iontophoretically applied noradrenaline (Cedarbaum \& Aghajanian, 1976). Golgi studies revealed that LC neurons have collateral branching of their axons (Shimizu \& Imamoto, 1970). Furthermore, in electron micrographs of the LC, synaptic terminals with dense-core vesicles can be seen (Hökfelt, 1967), which could represent axon collaterals of LC neurons (Shimizu \& Imamoto, 1970). However, the conclusion that poststimulus firing depression in the LC results from collateral inhibition via alpha-2 receptors has recently been strongly questioned by the same laboratory. Thus, recording in slices of LC, Andrade and Aghajanian (1984) found that piperoxane did not alter either spontaneous activity of LC neurons or the afterhyperpolarization that followed depolarizationinduced bursts of activity in LC neurons. It was suggested that the afterhyperpolarization that was responsible for postexcitation inhibition resulted from activation of a $\mathrm{Ca}^{2+}$ dependent $\mathrm{K}^{+}$conductance; no evidence was obtained for a dependence of this conductance on activation of alpha-2 receptors (Andrade \& Aghajanian, 1984).

How, then, can these findings be reconciled with the data collected by the same group in vivo? Some indications that the negative feedback loop mediated via alpha-2 receptors may not explain the entire inhibitory process can already be found in Cedarbaum and Aghajanian's (1976) original paper. First, the inhibitory phases were not completely blocked by piperoxane. Second, the doses of piperoxane which blocked firing depression did not increase the cells' spontaneous firing rate, which it should do if, indeed, there were a tonic noradrenergic input onto these cells. The possibility has also been considered that the discrepancy could be explained by the presence of a tonic activation of alpha- 2 receptors in the LC by extrinsic catecholaminergic inputs or recurrent collaterals. These inputs would be absent in slices (Andrade \& Aghajanian, 1984), and could tonically hyperpolarize LC neurons and explain why afterhyperpolarizations are reduced but not completely abolished by piperoxane in 
Table 1

Actions of Iontophoretically Administered Transmitter Candidates on the Spontaneous Firing Rate of Locus Coeruleus Neurons

\begin{tabular}{lc}
\hline \multicolumn{1}{c}{ Transmitter } & \multicolumn{1}{c}{ Investigators } \\
\hline & Inhibitory Actions \\
$\gamma$-aminobutyric acid & Cedarbaum \& Aghajanian, 1977 \\
Noradrenaline & Cedarbaum \& Aghajanian, 1977 \\
Adrenaline & Cedarbaum \& Aghajanian, 1977 \\
Serotonin & Segal, 1979 \\
Enkephalin & Young, Bird, \& Kuhar, 1977 \\
Neurotensin & Young, Uhl, \& Kuhar, 1978 \\
& Excitatory Actions \\
Acetylcholin & Young, Bird, \& Kuhar, 1977 \\
Glutamate & Guyenet \& Aghajanian, 1979 \\
CRF & Valentino, Foote, \& Aston-Jones, 1983 \\
ACTH & Olpe \& Jones, 1982 \\
Vasopressin & Olpe \& Baltzer, 1981 \\
Substance P & Guyenet \& Aghajanian, 1977 \\
\hline
\end{tabular}

Note - This is a summary of the results of microiontophoretic investigations in which various putative neurotransmitters were applied microiontophoretically near individual LC neurons. In all studies, extracellular recordings were performed.

vivo. Clearly, the physiological relevance of alpha-2 receptors on LC neurons needs to be studied in greater depth.

Afferent regulatory inputs to the LC. In functional terms, neuronal activity in the LC is influenced by both sensory and visceral inputs. In the anesthetized rat, LC neuronal discharge is influenced by sympathetic, parasympathetic (Elam, Yao, Svensson, \& Thoren, 1984), and noxious inputs (Cedarbaum \& Aghajanian, 1976). In contrast to the anesthetized preparation, the important activating action of all kinds of sensory inputs on LC neurons has been well documented in the awake animal (AstonJones \& Bloom, 1981; Foote, Aston-Jones, \& Bloom, 1980). However, the afferent systems that mediate the above-mentioned effects remain to be elucidated.

On the basis of findings from anatomical and iontophoretic studies, it seems likely that the LC may receive extrinsic input from many systems. Thus many putative transmitters have been located in terminals in the LC and the sensitivity of LC neurons to these substances has been documented. Table 1 summarizes the findings of the latter studies. If one assumes that iontophoretic application of a substance results in activation of synaptic receptors for this substance, then it seems that LC neuronal activity could be controlled by a large variety of putative excitatory and inhibitory transmitters. Unfortunately, definite conclusions concerning these possibilities cannot be reached with regard to the functionality of these possible inputs. Indeed, in many cases, the location of the projection neurons giving rise to these substances in the LC is unknown. Thus, although many of these substances may be involved in the extrinsic functional regulation of LC activity, assignment of a particular transmitter to the mediation of a particular influence must await rigorous correlative, pharmacological, and physiological investigations.

\section{The Concepts of LC Output}

Inhibitory and excitatory effects of noradrenaline on postsynaptic neurons. The rather extensive literature bearing on this issue has been discussed in several previous reviews (Foote, Bloom, \& Aston-Jones, 1983; Szabadi, 1979; Van Dongen, 1981). Only a brief account is presented here. Microiontophoretically applied noradrenaline can elicit both depressions and excitations of spontaneous neuronal activity in many areas of the anesthetized mammalian brain. In most instances, depressant effects of noradrenaline have been antagonized by beta-adrenergic blocking agents. Synaptically released noradrenaline evoked by electrical stimulation of the LC can elicit qualitatively similar depressant effects, and these are generally also blocked by beta-receptor blocking compounds (Olpe, Glatt, Laszlo, \& Schellenberg, 1980). A considerable number of studies have reported that iontophoretically applied noradrenaline can activate target neurons in several brain regions. Excitatory effects have been observed in the neocortex (Bevan, Bradshaw, \& Szabadi, 1977), the dorsal lateral geniculate (Baraban \& Aghajanian, (1980), and the facial motor nucleus (Van der Maelen \& Aghajanian, 1980). Unfortunately, it is still not very clear which receptors are mediating excitatory and inhibitory effects of noradrenaline. A detailed discussion of the rather confusing literature would be beyond the scope of this paper.

Modulatory effects of noradrenaline. The earlier concept that noradrenaline acts in the central nervous system as a classical inhibitory and/or excitatory transmitter has been challenged in the past couple of years by findings in several laboratories that noradrenaline is capable of strongly modifying the effects of other putative transmitters. In these studies, the spontaneous cell activity was either unaffected or depressed during exposure to synaptically released or iontophoretically administered noradrenaline, and at the same time the response of the same target neuron to other transmitter candidates was reduced or potentiated.

In the first type of experiment, a modulatory effect has been observed in studies in which both noradrenaline and the test transmitter were applied iontophoretically. Figure 2 depicts brain areas in which such investigations have been conducted. In the second type of experiment, the effect of iontophoretically or synaptically released noradrenaline on synaptically elicited responses of other cell systems was investigated. Figure 3 depicts schematically where these experiments have been performed. Taken together, Figures 2 and 3 demonstrate that the noradrenergic system may modify a considerable number of other transmitter systems throughout the brain. Thus, it has been suggested that the depressant effects of GABA and the excitatory effects of acetylcholine and glutamate on single cells are facilitated or enhanced by noradrenaline and the noradrenergic system (Moises \& Woodward, 1980; Moises, Woodward, Hoffer, \& Freedman, 1979; Segal, 1982; Waterhouse, Moises, \& Woodward, 1981). In contrast, other workers have suggested that noradrenaline may, in fact, depress the responsive- 


\section{MODULATION OF TRANSMITTER SENSITIVITY}

\section{BY NORADRENALINE}

\section{SENSORY MEURONS}

ACh 4 (a-mediated)

(Waterhouse et al., 1981)

CINGULATE CORTICAL NEURONS

CORTICAL NEURONS

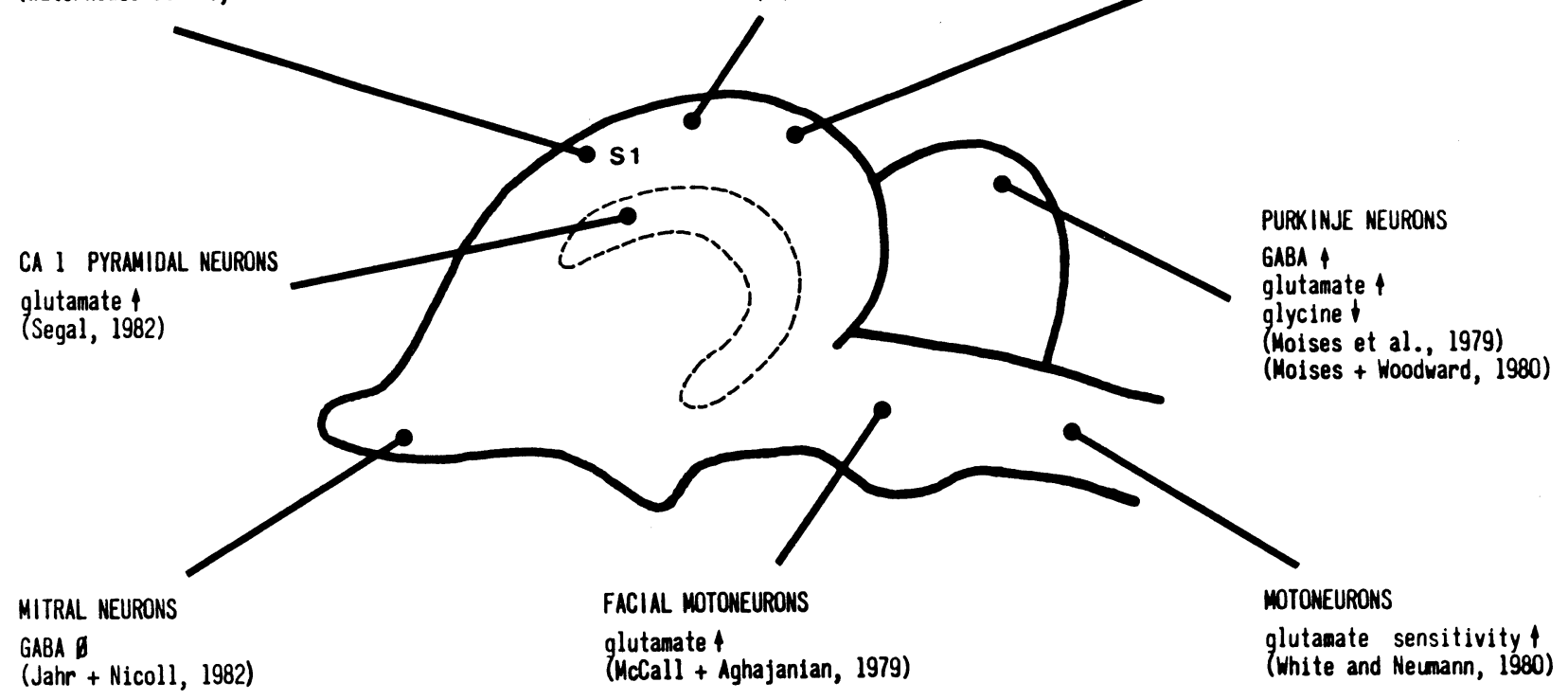

Figure 2. Brain areas are indicated in which iontophoretic studies have demonstrated an interaction of noradrenaline with other neurotransmitters in terms of altered transmitter sensitivity.

\section{MODULATION OF SYNAPTIC RESPONSES \\ BY NORADRENALINE}

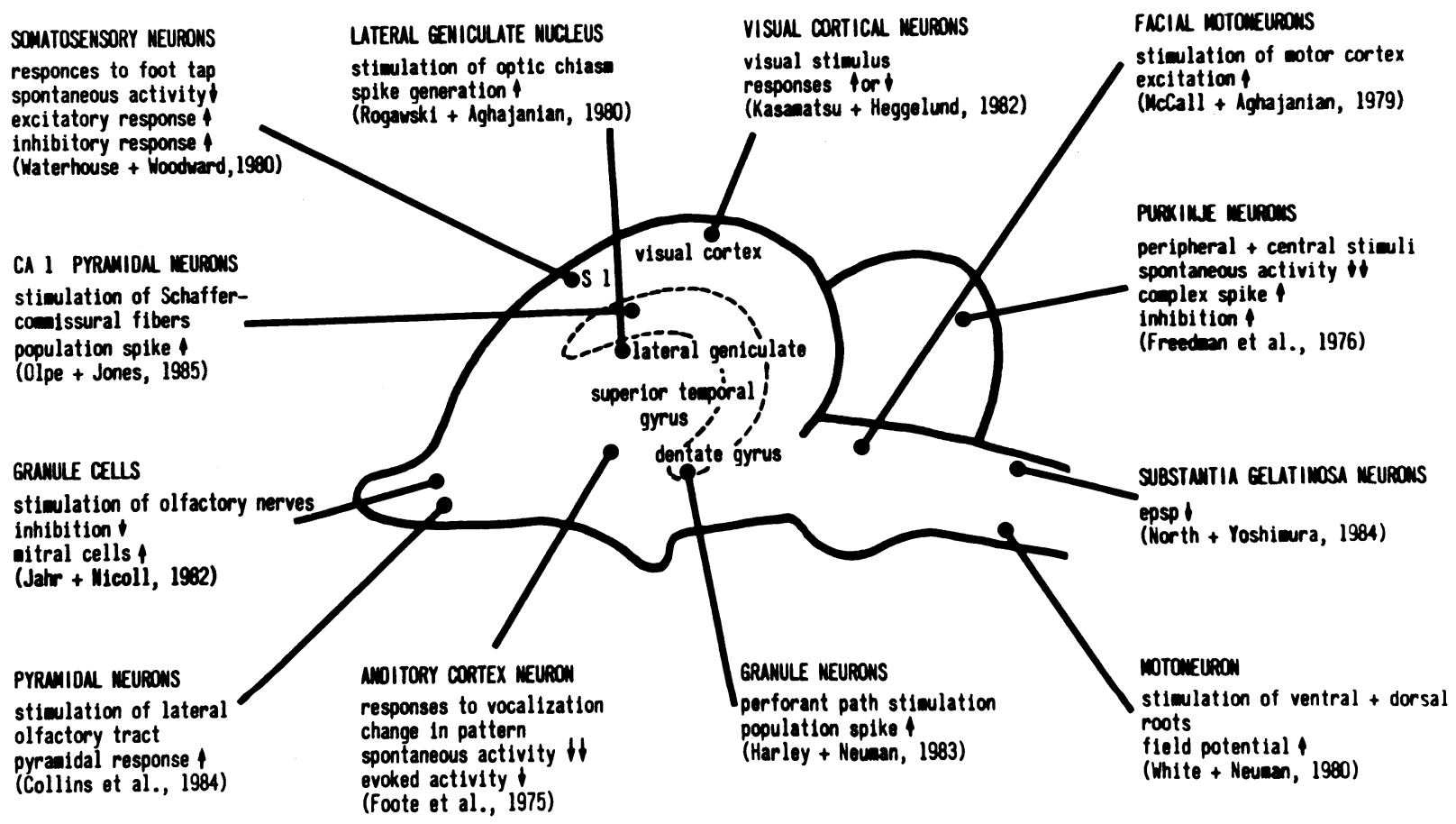

Figure 3. Brain regions are indicated in which iontophoretically or synaptically released noradrenaline has been shown to interact with other synaptically released transmitters. 
ness of cells to acetylcholine (Reader, Ferron, Descarries, \& Jasper, 1979). Excitatory effects of the neuropeptide substance $P$ on cortical cells are depressed by both noradrenaline and the noradrenergic system (Jones \& Olpe, 1984, in press). Figure 3 indicates that synaptic responses of cells in many brain areas are strongly modified by noradrenaline.

In several instances, the common effect on spontaneously occurring cellular activity is cell depression, whereas the evoked response is strengthened. This phenomenon has been described for the cerebellum (Freedman, Hoffer, \& Woodward, 1976) and the cortical somatosensory neurons (Waterhouse \& Woodward, 1980). In other cases, both spontaneous and evoked activity are reduced, but the former to a greater degree than the latter. In the monkey auditory cortex, noradrenaline reduced spontaneous activity to a larger extent than it reduced vocalization-induced activity (Foote, Freedman, \& Oliver, 1975). This has been interpreted as indicating that noradrenaline increases the "signal-to-noise" ratio (Waterhouse \& Woodward, 1980), that is, depresses background activity but preserves evoked activity. This concept certainly represents an interesting hypothesis to help explain how the LC may mediate its beneficial effect on cognitive functions. However, it should be stressed that it remains to be convincingly shown whether, indeed, LC activation results in improvement of cognitive processes. Furthermore, noradrenaline released from LC terminals exerts such a multitude of actions (Figures 2 and 3 ) that they cannot be reconciled by this concept alone. The recently discovered suppressing effect of both locally applied and synaptically released noradrenaline on cortical substance $\mathrm{P}$ sensitivity is just opposite to the facilitating actions described for noradrenaline on acetylcholine and glutamate responsiveness. The physiological significance of this effect remains to be elucidated.

A possible explanation for the facilitation of excitatory responses (e.g., to acetylcholine or glutamate) by noradrenaline has been suggested by recent intracellular studies on hippocampal pyramidal cells. Thus, application of a depolarizing pulse to these cells evokes action potentials, but a rapid accommodation is seen during the pulse. Noradrenaline blocks this accommodation and allows for the enhancement of the number of action potentials produced by the depolarization (Haas \& Konnerth, 1983; Madison \& Nicoll, 1982). This effect may be due to a noradrenaline-mediated inhibition of a $\mathrm{Ca}^{2+}$-activated $\mathrm{K}^{+}$conductance. Segal (1982) has also shown that depolarizing responses of hippocampal cells to glutamate are enhanced by noradrenaline. Although these findings are difficult to reconcile with earlier studies showing that noradrenaline is a depressant agent in the hippocampus in vivo (Segal \& Bloom, 1974), they are in keeping with in vitro data demonstrating that noradrenaline increases the population spike recorded from CA1 pyramidal neurons (Mueller, Hoffer, \& Dunwiddie, 1981; Mueller, Palmer, Hoffer, \& Dunwiddie, 1982). In preliminary extracellular experiments, we recently observed that acti- vation of LC neurons also results in increased pyramidal cell excitability in vivo (Olpe \& Jones, in press; Olpe, Jones, Laszlo, Waldmeier, \& Maitre, 1985). Progress in our understanding of noradrenaline actions on target neurons will be provided by in vivo intracellular studies in which noradrenaline is released synaptically. Studies in vitro on slices, although offering a number of technical advantages over in vivo work, are hampered by the fact that the compounds investigated may potentially act on both synaptic and extrasynaptic receptors and by the fact that the slices are usually exposed to the drugs for a prolonged period, thus allowing desensitization to develop.

\section{POSSIBLE VEGETATIVE FUNCTIONS THE OF LC}

The electrophysiological findings outlined in the previous section can be reconciled with the hypothesis that the LC is involved in the control or regulation of cognitive processes. Studies on the spontaneous discharge characteristics of LC noradrenergic neurons in conscious animals are in keeping with this notion (Aston-Jones \& Bloom, 1981). However, in recent years, an increasing number of investigations have been published suggesting that LC neurons may also have a role in the control of vegetative functions.

Increases in blood pressure (BP) have been reported in numerous studies in which the area of the LC was activated by electrical stimulation (Kawamura, Gunn, \& Frohlich, 1978; Fallert \& Polc, 1970; Ward \& Gunn, 1976). The LC has also been reported to affect gastric functions (Osumi, Ishikawa, Okuma, Nagasaka, \& Fujiwara, 1981) and the urinary bladder (Osumi, Oishi, Fujiwara, \& Takaori, 1975). These data provide sufficient evidence to support the hypothesis that the LC has a role in the vegetative sphere.

The first report suggesting that the LC is involved in central BP regulation came from Fallert and Polc (1970), who found an increase in BP evoked by stimulation of the LC area in the rabbit. These findings were later confirmed and extended to other species, including rats (Chida, Kawamura, \& Hatano, 1983; Kawamura et al., 1978) and cats (Buchweitz, Edelman, \& Weiss, 1985; Goadsby, Lambert, \& Lance, 1983; Gurtu, Pant, Sinha, \& Bhargava, 1984; Katayama, Ueno, Tsukiyami, \& Tsubokawa, 1981; Przuntek \& Phillipu, 1983; Ward \& Gunn, 1976). All these studies reported pressor effects of LC stimulation. Some caution should be exercised with regard to these results, since it has not been demonstrated whether the increase in BP is mediated via noradrenergic neurons or possibly other neurons and/or fibers of passage. Electrical stimulation experiments are hampered by current spread, which is difficult to control. A selective stimulation of LC neurons appears to be a formidable task in view of the small size and elongated flat shape of the LC area. Berecek, Olpe, Jones, and Hofbauer (1984) have tried to chemically activate LC neu- 
rons in the awake rat by means of injecting small amounts of vasopressin into the LC area in chronically implanted awake animals. The rationale for these experiments is based on the observation that vasopressin is present in the LC area and that the peptide is able to activate LC neurons if applied microiontophoretically (Olpe \& Baltzer, 1981). It was found that injections of nanogram quantities of vasopressin elicited pronounced increases in both BP and heart rate. Since the effect was blocked by an alpha-blocking agent, it was concluded that the action was mediated via activation of the peripheral sympathetic nervous system. It remains to be shown, however, whether the changes in cardiovascular parameters are mediated via activation of noradrenergic neurons of the LC, although this appears to be the most likely conclusion at the moment.

Lesioning of the LC should result in a reduction of BP if LC neurons were to exert a tonic activating effect on the cardiovascular system. In one study, lesioning of the dorsal noradrenergic bundle by means of the selective neurotoxin 6-OHDA resulted in the lowering of basal blood pressure in rats (Lightman, Todd, \& Everitt, 1984). In our own preliminary experiments, in which we lesioned the LC bilaterally by various methods, we consistently found a reduction in mean arterial BP (Berecek, Olpe, \& Hofbauer, 1985a). Clearly, additional experiments on animals with selective LC lesions will be required before any firm conclusions may be drawn. However, in view of these findings, it would be rather surprising if future studies did not confirm a role for the LC in BP regulation.

The electrophysiological studies bearing on this issue are not so consistent. LC neurons have been reported to be sensitive to peripheral BP changes (Andrade \& Aghajanian, 1982; Elam et al., 1984; Olpe, Berecek, et al., 1985; Svensson, Elam, Yao, \& Thoren, 1980), although others have found these neurons to be insensitive (Guyenet \& Byrum, 1985). In two studies, LC neurons were found to respond reciprocally to peripherally induced changes in BP (Andrade \& Aghajanian, 1982; Svensson et al., 1980). In another very recent study, the responsiveness of LC neurons to peripheral BP changes was found to be mixed (Olpe, Berecek, et al., 1985). The majority of neurons showed reciprocal changes in activity, but some neurons were activated during peripheral, prolonged rises in BP and some were insensitive (Olpe, Berecek, et al., 1985). The changes in cellular activity induced by elevation of BP were found either to be transient (Elam et al., 1984) or to outlast the period of pressure rise (Olpe, Berecek, et al., 1985). The mechanisms through which LC neurons are affected by BP changes remain to be elucidated. Deafferentation of arterial baroreceptors was found to have no effect on LC neuronal BP sensitivity (Elam et al., 1984).

LC neuronal activity appears to be affected also in chronic forms of hypertension. Svensson, Engberg, and Thoren (1979) reported that the average firing rate of LC noradrenergic neurons was progressively reduced with increasing BP and age in spontaneously hypertensive rats
(SHR). In a recent study, Olpe, Berecek, et al. (1985) confirmed that the mean firing rate of LC cells is reduced by $25 \%$ in DOCA-salt hypertensive animals and by $19 \%$ in SHR relative to the corresponding control rats of the same age. These findings were recently confirmed (Berecek, Olpe, \& Hofbauer, 1985b). It would be interesting to conduct similar investigations in the prehypertensive phase, where different results may be expected.

What is the physiological relevance of these findings? Are all LC neurons or just a subpopulation of LC cells actively involved in central BP regulation? It may, of course, be that these neurons are merely sensitive to blood pressure changes and have no active function in its control. In the latter case, does the LC constitute a center for integrating autonomic with higher functions? This certainly is an interesting hypothesis. The stimulation experiments suggest that the LC is a pressor area. However, the findings are not conclusive, as mentioned above, because proper control experiments have not yet been performed. At the moment, these missing experiments are probably the most crucial for providing key information for directing future research. Interpretation of the electrophysiological data is hampered by the fact that the data have been collected mostly from anesthetized animals. In the conscious mammalian brain, the reactivity and spontaneous discharge pattern of LC cells under conditions of changed BP may be quite different. The fact that LC spontaneous discharge rate is reduced in two different forms of hypertension suggests that these neurons are not involved in the maintenance of increased BP. Similar conclusions were reached recently on the basis of selective lesion experiments. Lesions of the dorsal noradrenergic bundle by injection of 6-OHDA were shown to have no effect on the development of hypertension in SHR, whereas total depletion of central catecholamines did attenuate its development (Buuse, de Kloet, Versteeg, \& de Jong, 1984). In conclusion, the data on the function of the LC in BP regulation and its sensitivity to experimentally induced BP changes are not consistent. Crucial experiments which will allow more conclusive statements on the LC's involvement in central BP regulation to be made are missing.

Svensson and Thoren (1979) have shown that spontaneous LC firing rate is affected by blood volume load in the anesthetized rat, that the neurons respond to even small changes in blood volume with reciprocal changes in firing rate, and that this effect is mediated via vagal afferents. Hypercapnia and hypoxia, both of which have been shown to cause activation of brain noradrenaline turnover, were found to lead to increased neuronal activity in the LC (Elam, Yao, Thoren, \& Svensson, 1981).

It has also been proposed that the descending noradrenergic fibers arising from the LC play a role in regulation of the urinary bladder (Osumi, Oishi, Fujiwara, \& Takaori, 1975). Bilateral lesions of the LC induce a urinary disorder that manifests itself in a dilatation of the bladder, urinary retention, and hematuria (Osumi et al., 1975). Identical observations have recently been made in 
other laboratories (H. Kawamura, personal communication; Berecek et al., 1985b).

An inhibitory impact of the LC on gastric functions was postulated on the basis of stimulation experiments in which unilateral LC stimulations were found to reduce basal and induced levels of gastric acid secretion and mucosal blood flow (Osumi et al., 1981). These investigators suggested that LC neurons exert their inhibitory action at the level of the brainstem ala cinerea.

\section{CONCLUSIONS}

Our understanding of the physiology of LC neurons is complicated by the large number of factors that regulate or influence their activity and by the diversity of effects elicited by noradrenaline postsynaptically. Although the complexity of these experimental findings hampers the development of a unifying general concept of the function of the LC, a considerable number of observations are in keeping with its postulated role in the control of cognitive functions. This hypothesis is supported indirectly mainly by the fact that LC neurons respond to all kinds of sensory inputs which are accompanied by orienting responses of the organism (Aston-Jones \& Bloom, 1981). It is further supported by the observation that the "signalto-noise" ratio in various LC projection areas is increased as a consequence of LC activation. Taken together, these findings are in agreement with the concept that the LC may play a role in vigilanice (Aston-Jones \& Bloom, 1981; Koella, 1984) or attention control.

This concept is in keeping also with the notion that such drugs as antidepressants or amphetamine, which are thought to potentiate noradrenergic transmission, can increase alertness and positively affect cognitive functions. We have recently shown that a number of psychogeriatric drugs, used for the treatment of cognitive disturbances in elderly patients, share the ability to activate LC neuronal firing (Olpe, Jones, \& Steinmann, 1983; Olpe \& Steinmann, 1982). Among these drugs are vincamine, Hydergine, centrophenoxine, pyritinol, and piracetam. Such an activating action was observed also with nicotine, physostigmine, and caffeine (Olpe et al., 1983), compounds which are claimed to exert a beneficial action on cognitive function in both man and mammals. Although we do not claim that the LC is the main target structure for psychogeriatrics, nicotine, caffeine, or physostigmine, it is conceivable that the LC, through its effects on target cells, could mediate some of the beneficial effects of the compounds on cognitive functions.

There is a fairly large body of experimental data supporting a role of the LC in central BP regulation. However, stimulation and single-cell recording data appear to be at variance. If the LC is a pressor area, as suggested by stimulation experiments, one would expect that cellular activity should be greater in hypertensive animals than in normotensive animals. How can the two sets of data be reconciled? It is conceivable that electrical stimu- lation in normotensive animals, which occurred mostly at stimulation frequencies exceeding $20 \mathrm{~Hz}$, might have led to a depolarization blockade of these neurons, thus actually resulting in the opposite effect, namely firing depression. However, this is just a speculative possibility. One should also consider the possibility that electrical stimulation of the LC in hypertensive and normotensive animals elicits different effects on BP. Irrespective of the necessity to study this issue in greater depth, it is interesting that LC neurons are affected by chronic hypertension. These findings document that LC neurons are at least sensitive to BP, although it remains to be shown whether they play an active role in BP regulation.

In conclusion, there is a case for the LC's playing a role in both the cognitive and the vegetative spheres, but the exact role of this nucleus remains to be elucidated. This presentation focused on only two postulated functions of the LC. Given the possibility that the LC may have several additional functions, one has to postulate and search for the correlates of this functional heterogeneity in anatomical and cell physiological terms.

\section{REFERENCES}

Aghajanian, G. K., Cedarbaum, J. M., \& Wang, R. Y. (1977). Evidence for norepinephrine-mediated collateral inhibition of locus coeruleus neurons. Brain Research, 136, 570-577.

Andrade, R., \& Aghajanian, G. K. (1982). Single cell activity in the noradrenergic A-5 region: Responses to drugs and peripheral manipulations of blood pressure. Brain Research, 242, 125-135.

Andrade, R., \& Aghajanian, G. K. (1984). Locus coeruleus activity in vitro: Intrinsic regulation by a calcium-dependent potassium conductance but not alpha 2-adrenoceptors. Journal of Neuroscience, 4, 161-170.

Aston-Jones, G., \& Bloom, F. E. (1981). Norepinephrine-containing locus coeruleus neurons in behaving rats exhibit pronounced responses to non-noxious environmental stimuli. Journal of Neuroscience, 1 , $887-900$.

Baraban, J. M., \& Aghajanian, G. K. (1980). Suppression of firing activity of 5-HT neurons in the dorsal raphe by alpha-adrenoceptor antagonists. Neuropharmacology, 19, 355-363.

Berecek, K. H., Olpe, H.-R., \& Hofbauer, K. G. (1985a). The impact of lesioning locus coeruleus on blood pressure and heart rate. Manuscript in preparation.

BereceK, K. H., OlPE, H.-R., \& Hofbauer, K. G. (1985b). Increased sensitivity of locus coeruleus neurons to vasopressin in DOCA-salt hypertensive rats. Manuscript in preparation.

Berecek, K. H., Olpe, H.-R., Jones, R. S. G., \& Hofbauer, K. G. (1984). Microinjection of vasopressin into the locus coeruleus of conscious rats. American Journal of Physiology, 247, 675-681.

Bevan, P., Bradshaw, C. K., \& Szabadi, E. (1977). The pharmacology of adrenergic neuronal responses in the cerebral cortex: Evidence for excitatory alpha- and inhibitory beta-receptors. British Journal of Pharmacology, 59, 635-641.

Buchweitz, E., Edelman, N. H., \& Weiss, H. R. (1985). Effect of locus coeruleus stimulation on regional cerebral oxygen consumption in the cat. Brain Research, 325, 107-114.

Buuse, van den, M., de Kloet, E. R., Versteeg, D. H. G., \& DE JONG, W. (1984). Regional brain catecholamine levels and the development of hypertension in the spontaneously hypertensive rat: The effect of 6-hydroxydopamine. Brain Research, 301, 221-229.

Cedarbaum, J. M., \& Aghajanian, G. K. (1976). Noradrenergic neurons of the locus coeruleus: Inhibition by epinephrine and activation by the alpha-antagonist piperoxane. Brain Research, 112, 413-419. Cedarbaum, J. M., \& Aghajanian, G. K. (1977). Catecholamine 
receptors on locus coeruleus neurons: Pharmacological characterization. European Journal of Pharmacology, 44, 375-385.

Cedarbaum, J. M., \& Aghajanian, G. K. (1978). Activation of locus coeruleus neurons by peripheral stimuli: Modulation by a collateral inhibitory mechanism. Life Sciences, 23, 1383-1392.

Chida, K., Kawamura, H., \& Hatano, M. (1983). Participation of the nucleus locus coeruleus in DOCA-salt hypertensive rats. Brain Research, 273, 53-58.

Collins, G. G. S., Anson, J., \& Hammond, P. J. (1984). An unlikely role for cyclic ATIP in the mediation of the excitatory and inhibitory effect of noradrenaline on transmission in the olfactory cortex. Brain Research, 299, 344-347.

Elam, M., Yao, T., Svensson, T. H., \& Thoren, P. (1984). Regulation of locus coeruleus neurons and splanchnic, symphathetic nerves by cardiovascular afferents. Brain Research, 290, 281-287.

Elam, M., Yao, T., Thoren, P., \& Svensson, T. H. (1981). Hypercapnia and hypoxia: Chemoreceptor-mediated control of locus coeruleus neurons and splanchnic, sympathetic nerves. Brain Research, 222, 373-381.

FALlert, M., \& Polc, P. (1970). Blutdruckreizeffekte aus dem Locus Coeruleus, dem Ponto-bulbaeren Raphe-System und der medullaeren Formation reticularis beim Kaninchen. Archiv für Kreislaufforschung, 62, 153-166.

Foote, S., Aston-Jones, G., \& Bloom, F. E. (1980). Impulse activity of locus coeruleus neurons in awake rats and squirrel monkeys is a function of sensory stimulation and arousal. Proceedings of the $\mathrm{Na}$ tional Academy of Sciences, 77, 3033-3037.

Foote, S. L., BLoOM, F. E., \& Aston-Jones, G. (1983). Nucleus locus coeruleus: New evidence of anatomical and physiological specificity. Physiological Reviews, 63, 844-913.

Foote, S. L., Freedman, R., \& Oliver, A. P. (1975). Effects of putative neurotransmitters on neuronal activity in monkey auditory cortex. Brain Research, 86, 229-242.

FreEdMAN, R., HofFer, B. J., \& WoOdWARD, D. J. (1976). Noradrenaline modulation of the responses of the cerebellar purkinje cell to afferent synaptic activity. British Journal of Pharmacology, 57, 603-605.

GoadSBy, P. J., LAMBerT, G. A., \& LANCE, J. W. (1983). Effects of locus coeruleus stimulation on carotid vascular resistance in the cat. Brain Research, 278, 175-183.

Gurtu, S., Pant, K. K., Sinha, J. N., \& Bhargava, K. P. (1984). An investigation into the mechanism of cardiovascular responses elicited by electrical stimulation of locus coeruleus and subcoeruleus in the cat. Brain Research, 301, 59-64.

Guyenet, P. G., \& Aghajanian, G. K. (1977). Excitation of neurons in the nucleus locus coeruleus by substance $P$ and related peptides. Brain Research, 136, 178-184.

Guyenet, P. G., \& Aghajanian, G. K. (1979). ACh, substance P and metenkephalin in the locus coeruleus: Pharmacological evidence for independent sites of action. European Journal of Pharmacology, 33, 319-328.

GUYENET, P. G., \& Byrum, C. E. (1985). Comparative effects of sciatic nerve stimulation, blood pressure, and morphine on the activity of A5 and A6 pontine noradrenergic neurons. Brain Research, 327, 191-201.

HAAS, H. L., \& KonNerTh, A. (1983). Histamine and noradrenaline decrease calcium-activated potassium conductance in hippocampal pyradmidal cells. Nature, 302, 432-434.

Hagan, J. J., Alpert, J. E., Morris, R. G. M., \& Iversen, S. D. (1983). The effects of central catecholamine depletions on spatial learning in rats. Behavioural Brain Research, 9, 83-104.

Harley, C. W., \& NeUman, R. S. (1983). Long-lasting potentiation of the dentate gyrus population spike by norepinephrine. Brain Research, 273, 162-165.

Heritage, A. S., Grant, L. D., \& StumpF, W. E. (1977). 3 H-Estradiol in catecholamine neurons of rat brainstem: Combined localization by antoradiography and formaldehyde-induced fluorescence. Journal of Comparative Neurology, 176, 607-630.

HöKFELT, T. (1967). On the ultrastructural localization of noradrenaline in the central nervous system of the rat. Zeitschrift für Zellforschung, 79, 110-117.
JAHR, C. E., \& NiCOLL, R. A. (1982). Noradrenergic modulation of alpha-endrodendritic inhibition in the olfactory bulb. Nature, 297, 227-229.

JoNeS, R. S. G., \& OLPE, H. -R. (1984). Activation of the noradrenergic projection from locus coeruleus reduces the excitatory responses of anterior cingulate cortical neurons to substance P. Neuroscience, 13, 819-825.

JONES, R. S. G., \& OLPE, H. -R. (in press). Pharmacological characterization of the receptor mediating the adrenergic inhibition of responses to substance $\mathrm{P}$ in the cingulate cortex. Brain Research.

Kasamatsu, T., \& Heggelund, P. (1982). Single cell responses in cat visual cortex to visual stimulation during iontophoresis of noradrenaline. Experimental Brain Research, 45, 317-327.

Katayama, Y., Ueno, Y., TsukiYama, T., \& TsubokaWa, T. (1981). Long lasting suppression of firing of cortical neurons and decrease in cortical blond flow following train pulse stimulation of the locus coeruleus in the cat. Brain Research, 216, 173-179.

Kawamura, H., Gunn, C. G., \& Frohlich, E. D. (1978). Cardiovascular alteration by nucleus locus coeruleus in spontaneously hypertensive rat. Brain Research, 140, 137-147.

Koella, W. P. (1984). The organization and regulation of sleep: A review of the experimental evidence and a novel integrated model of the organizing and regulating apparatus. Experientia, 40, 309-338.

Lightman, S. L., TodD, K., \& Everitt, B. J. (1984). Ascending noradrenergic projections from the brainstem: Evidence for a major role in the regulation of blood pressure and vasopressin secretion. Experimental Brain Research, 55, 145-151.

Madison, D. V., \& Nicoll, R. A. (1982). Noradrenaline blocks accommodation of pyramidal cell discharage in the hippocampus. $\mathrm{Na}$ ture, 299, 636-638.

MaIR, R. G., \& McEnTEe, W. J. (1983). Korsakoff's psychosis: Noradrenergic systems and cognitive impairment. Behavioural Brain Research, 9, 1-32.

McCall, R. B., \& Aghajanian, G. K. (1979). Serotonergic facilitation of facial motoneuron excitation. Brain Research, 169, 11-27.

MoISES, H. C., \& WoodwARD, D. J. (1980). Potentiation of GABA inhibitory action in cerebeilum by locus coeruleus stimulation. Brain Research, 182, 327-344.

Moises, H. C., Woodward, D. J., Hoffer, B. J., \& Freedman, R. (1979). Interactions of norepinephrine with purkinje cell responses to putative amino acid neurotransmitters applied by microiontophoresis. Experimental Neurology, 64, 493-515.

Mueller, A. L., Hoffer, B. J., \& Dunwiddie, T. V. (1981). Noradrenergic responses in rat hippocampus: Evidence for mediation by alpha and beta receptors in the in vitro slice. Brain Research, 214, 113-126.

Mueller, A. L., Palmer, M. R., Hoffer, B. J., \& Dunwiddie, T. V. (1982). Hippocampal noradrenergic responses in vivo and in vitro/characterization of alpha and beta components. NaunynSchmiedeberg's Archiv für Pharmakologie, 318, 259-266.

NoRTH, R. A., \& Yoshimura, M. (1984). The actions of noradrenaline on neurons of the rat substantia gelatinosa in vitro. Journal of Physiology (London), 349, 43-55.

OLPE, H.-R., \& BALTZER, V. (1981). Vasopressin activates noradrenergic neurons in the rat locus coeruleus: A microiontophoretic investigation. European Journal of Pharmacology, 73, 377-378.

OlPE, H.-R., BereceK, K., Jones, R. S. G., Steinmann, M. W., SonNENBURG, C., \& HoFBAUER, K. G. (1985). Reduced activity of locus coeruleus neurons in SHR and DOCA-salt rats. Manuscript submitted for publication.

Olpe, H.-R., Glatt, A., Laszlo, J., \& Schellenberg, A. (1980). Some electrophysiological and pharmacological properties of the cortical, noradrenergic projection of the locus coeruleus in the rat. Brain Research, 186, 9-19.

OLPE, H.-R., \& JONES, R. S. G. (1982). Excitatory effects of ACTH on noradrenergic neurons of the locus coeruleus in the rat. Brain Research, 251, 177-179.

OLPE, H.-R., \& JoNES, R. S. G. (in press). Glutamate-induced activation of locus coeruleus facilitates hippocampal pyramidal cell excitability. Neuroscience Letters. 
Olpe, H.-R., Jones, R. S. G., Laszlo, J., Waldmeier, P. C., \& MAITRE, L. (1985). The facilitating action of locus coeruleus activation on CA1 pyramidal cell excitability and on transcallosally elicited cortical field potentials in vivo. Neuroscience Abstracts, 312, 15.

OlPe, H.-R., Jones, R. S. G., \& SteinmanN, M. W. (1983). The locus coeruleus: Actions of psychoactive drugs. Experientia, 39, 242-249.

Olpe, H.-R., \& Steinmann, M. W. (1982). The effect of vincamine, hydergine and piracetam on the firing rate of locus coeruleus neurons. Journal of Neural Transmission, 55, 101-109.

Osumi, Y., Ishikawa, T., Okuma, Y., Nagasaka, Y., \& Fujiwara, M. (1981). Inhibition of gastric functions by stimulation of the rat locus coeruleus. European Journal of Pharmacology, 75, 27-35.

Osumi, Y., Oishi, R., Fujiwara, H., \& TAKaORI, S. (1975). Hyperdipsia induced by bilateral destruction of the locus coeruleus in rats. Brain Research, 86, 419-429.

Pisa, M., \& Fibiger, H. C. (1983). Evidence against a role of the rat's dorsal noradrenergic bundle in selective attention and place memory. Brain Research, 272, 319-329.

Przuntek, H., \& Phillipu, A. (1983). Reduced pressor responses to stimulation of the locus coeruleus after lesion of the posterior hypothalamus. Naunyn-Schmiedeberg's Archiv für Pharmakologie, 276, 119-122.

Reader, T. A., Ferron, A., Descarries, L., \& Jasper, H. H. (1979). Modulatory role for biogenic amines in the cerebral cortex: Microiontophoretic studies. Brain Research, 160, 217-229.

Rogawski, M. A., \& Aghajanian, G. K. (1980). Activation of lateral geniculate neurons by norepinephrine: Mediation by an alphaadrenergic receptor. Brain Research, 182, 345-359.

SEgAL, M. (1979). Serotonergic innervation of the locus coeruleus from the dorsal raphe and its action on responses to noxious stimuli. Journal of Physiology (London), 286, 401-415.

Segal, M. (1982). Norepinephrine modulates reactivity of hippocampal cells to chemical stimulation in vitro. Experimental Neurology, 77, 86-93.

Segal, M., \& Bloom, F. E. (1974). The action of norepinephrine in the rat hippocampus: II. Activation of the input pathway. Brain Research, 72, 99-114.

ShimzU, N., \& Iмамото, K. (1970). Fine structure of the locus coeruleus in the rat. Archivum Histologicum Japanicum, 31, 229-246.

Svensson, T. H., Elam, M., YAo, T., \& Thoren, P. (1980). Parallel regulation of brain norepinephrine (NE) neurons and peripheral, splandenic NE nerves by chemoreceptors, baroreceptors and blood volume receptors. Neuroscience Abstracts, 6, 234.
Svensson, T. H., Engberg, G., \& Thoren, P. (1979). Activity of brain noradrenergic neurons in spontaneously hypertensive rats. Acta Physiologica Scandinavica Supplement, 473, 12.

Svensson, T. H., \& THOREN, P. (1979). Brain noradrenergic neurons in the locus coeruleus: Inhibition by blood volume load through vagal afferents. Brain Research, 172, 174-178.

SzaBADI, E. (1979). Adrenoceptors on central neurones: Microelectrophoretic studies. Neuropharmacology, 18, 831-843.

Valentino, R. J., Foote, S. L., \& Aston-Jones, G. (1983). Corticotropin-releasing factor activates neurons of the locus coeruleus. Brain Research, 270, 363-367.

Van Der Maelen, C. P., \& Aghajanian, G. K. (1980). Intracellular studies showing modulation of facial motoneurone excitability by serotonin. Nature, 287, 346-347.

VAN Dongen, P. A. M. (1981). The central noradrenergic transmission and the locus coeruleus: A review of the data and their implications for neurotransmission and neuromodulation. Progress in Neurobiology, 16, 117-143.

WARD, D. G., \& GuNN, C. G. (1976). Locus coeruleus complex: Elicitation of a pressor response and a brainstem region necessary for its occurrence. Brain Research, 107, 401-406.

Waterhouse, B. D., Moises, H. C., \& Woodward, D. J. (1981). Alpha-receptor-mediated facilitation of somatosensory cortical neuronal responses to excitatory synaptic inputs and iontophoretically applied acetylcholine. Neuropharmacology, 20, 907-920.

WATERHOUSE, B. D., \& WOODWARD, D. J. (1980). Interaction of norepinephrine with cerebrocortical activity evoked by stimulation of somatosensory afferent pathways in the rat. Experimental Neurology, 67, 11-34.

White, S. R., \& Neuman, R. S. (1980). Facilitation of spinal motoneurone excitability by 5 -hydroxytryptamine and noradrenaline. Brain Research, 188, 119-127.

Williams, J. T., North, R. A., Shefner, S. A., Nishi, S., \& Egan, T. M. (1984). Membrane properties of rat locus coeruleus neurones. Neuroscience, 13, 137-156.

Young, W. S., BIRD, S. Y., \& KUHAR, M. J. (1977). Iontophoresis of methionine-enkephalin in the locus coeruleus area. Brain Research, 129, 366-390.

Young, W. S., Uhl, G. R., \& KuHAR, M. J. (1978). Iontophoresis of neurotensin in the area of the locus coeruleus.Brain Research, 150, 431-435.

(Manuscript received April 16, 1985; revision accepted for publication December 10, 1985.) 